\title{
Effects of Exogenous Glucagon and Epinephrine in Physiological Amounts on the Blood Levels of Free Fatty Acids and Glycerol in Dogs*
}

\author{
W. A. Muller**, T.T. Aoki, R.H. Egdahl and G.F. Cahill, Jr. \\ Elliott P. Joslin Research Laboratory, Harvard Medical School, Dept. of Surgery, Boston, University Medical Center, Boston, MA, USA, \\ and Institut de Biochimie Clinique, University of Geneva, Geneva, Switzerland
}

Summary. Exogenous glucagon or epinephrine were infused into normal overnight fasted dogs to raise circulating hormone levels to concentrations within the physiologic range. Plasma levels of glycerol and free fatty acids remained unchanged during the glucagon infusion, but rose significantly during the administration of epinephrine. Plasma insulin in the systemic circulation remained unchanged during the glucagon infusion and increased slightly during the infusion of the catecholamine. The data suggest that in normal dogs glucagon in physiological amounts has no lipolytic effect. The importance of the sympathetic nervous system in regulating lipolysis in normal mammals is stressed.

Key words: Dog, glucagon effects, epinephrine effects, lipolysis, free fatty acids, glycerol.

The metabolic role of glucagon in man is still controversial [25, 21]. In particular, it is not certain whether the lipolytic effect of pharmacological amounts of glucagon well known to occur both in vitro [8] and in vivo [15], is of physiological significance. In 1966, Lefèbvre et al. [14] reported that infusions of physiological quantities of glucagon into the portal vein of dogs were associated with an increase in the plasma concentrations of free fatty acids (FFA). Unfortunately, they were unable at that time to measure circulating levels of this hormone during those experi-

* Supported in part by U.S.P.H.S. grants AM-05077, AM-15191, AM-17456, G.M.-17366, D.A.D.A.-17-67-C-7149 and Swiss National Science Foundation Grant 3.1060.73-

** Work carried out during the tenure at the E.P. Joslin Research Laboratory ments. However, Cherrington et al. [3] infused physiological quantities (calculated) systemically into pancreatectomized dogs and were unable to confirm Lefèbvre's findings, i.e. plasma FFA levels did not change.

In an attempt to resolve the question of whether or not the infusion of physiological quantities of glucagon is associated with lipolysis, dogs were infused with this hormone, and circulating levels of glucagon were monitored. Since it was adipose tissue lipolysis that was of interest, glucagon was administered into the systemic circulation to minimize its effect, if any, on hepatic lipid metabolism under these conditions. For comparison, epinephrine was infused in a similar fashion.

The amounts of the two hormones to be administered were chosen such that their respective plasma concentrations would not exceed those observed in pathophysiological situations. One such situation is insulin-induced hypoglycaemia in dogs, during which epinephrine secretion rates of close to $200 \mu \mathrm{g} / \mathrm{kg} / \mathrm{min}$ and plasma glucagon increases of three times baseline values have been observed [13]. In addition, diabetic ketoacidosis and hyperosmolar coma in man may be associated with markedly increased levels of glucagon $[11,16]$.

\section{Material and Methods}

Adult, overnight fasted mongrel dogs weighing between 20 and $32 \mathrm{~kg}$ were studied. Bilateral jugular vein catheters were inserted at least three days prior to the experiments. The tip of the right jugular vein catheter (infusion vessel) rested in the right auricle, while the tip of the left jugular vein (blood sampling vessel) catheter lay in the arch of the left subclavian vein. 
Glucagon (Eli Lilly, lot no. 6PD 86C) was infused into four dogs at a rate of $3.5 \mathrm{ng} / \mathrm{kg} / \mathrm{min}$ in saline containing 8/1000 dog serum (v/v). Epinephrine (Parke-Davis, lot no. LB104) was given at 200 $\mathrm{ng} / \mathrm{kg} / \mathrm{min}$ in saline in five dogs. In both types of experiments the volume infused over 60 min was 52 $\mathrm{ml}$. The insulin content of similar glucagon preparations amounts to $0.02 \%$ (i.e. 100 ng of glucagon containing $0.02 \mathrm{ng}$ of insulin).

Blood samples were collected as follows: six ml (for glucose, glucagon, insulin) into a tube containing $12 \mathrm{mg}$ EDTA $\mathrm{Na}_{2}$ and $0.3 \mathrm{ml}$ of Trasylol ${ }^{1}(500 \mathrm{Kal}-$ likrein Inhibitor Units per $\mathrm{ml}$ of blood), two $\mathrm{ml}$ (for free fatty acids) into a tube containing sodium heparin, and another two $\mathrm{ml}$ into a tube containing two $\mathrm{ml}$ (for glycerol) of perchloric acid ( 30 per cent). Glucose was measured in a Technicon autoanalyser using ferricyanide according to Hoffman et al. [9]. Free fatty acids were determined by the Trout, Estes and Friedberg [23] modification of the Dole method [4]. Glycerol was measured enzymatically [2]. Insulin and glucagon were determined by radioimmunoassay, as described $[22,24,12]$. The glucagon antiserum $30-K$, specific for pancreatic glucagon, was kindly donated by Dr. R.H. Unger, University of Texas, Southwestern Medical School, Dallas.

\section{Results}

The elevation of plasma glucagon obtained by an infusion of $3.5 \mathrm{ng} / \mathrm{kg} / \mathrm{min}$ was accompanied by a rise in plasma glucose of 4,5 and $12 \mathrm{mg}$ per $100 \mathrm{ml}$ respectively in 3 dogs, whereas a fall of $5 \mathrm{mg}$ per $100 \mathrm{ml}$ was observed in the fourth animal (Fig. 1). Neither the levels of FFA nor those of glycerol were significantly altered by the glucagon infusion. Similarly, no change in plasma insulin was detected in the systemic circulation.

In contrast to the above, epinephrine significantly increased plasma levels of both FFA and glycerol (Fig. 2). As an additional measure of control the heart rate was assessed in these animals by palpation. It was, as one would expect, elevated to 150 beats per min. Modest, but significant, rises of plasma insulin and glucose levels were observed at 15 to $30 \mathrm{~min}$ of the infusion, in agreement with Robertson's data in humans [18]. In contrast to the results of Gerich et al. [5] obtained in man, the epinephrine infusion was not accompanied by an increase in plasma glucagon. The experimental protocol used in this study cannot, however, exclude a small rise of glucagon in the portal circulation.

\footnotetext{
1 Trasylol ${ }^{\circledR}$, registered in Germany; gift from Dr. Ruff, BayerPharma A. G., Zürich, Switzerland
}

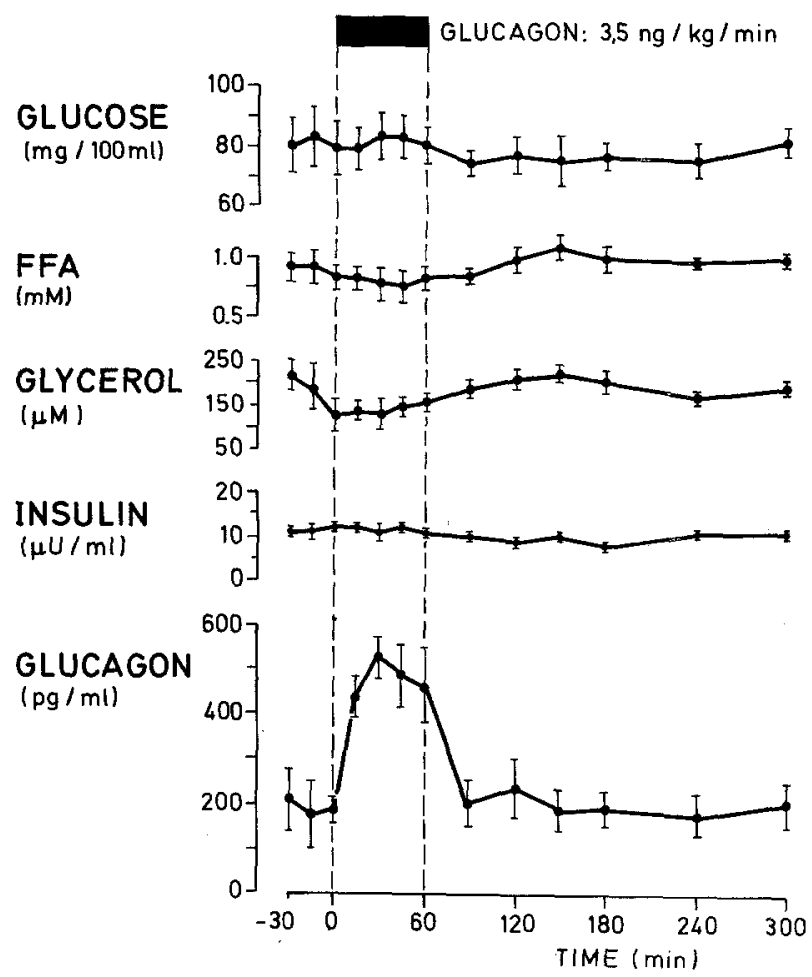

Fig. 1. The effect of glucagon on plasma levels of glucose, FFA, glycerol, insulin and glucagon. Glucagon was infused for one hour at a rate of $3.5 \mathrm{ng} / \mathrm{kg} / \mathrm{min}$ into four dogs. Means \pm SEM are given. With the exception of glucagon, no significant changes in levels were noted

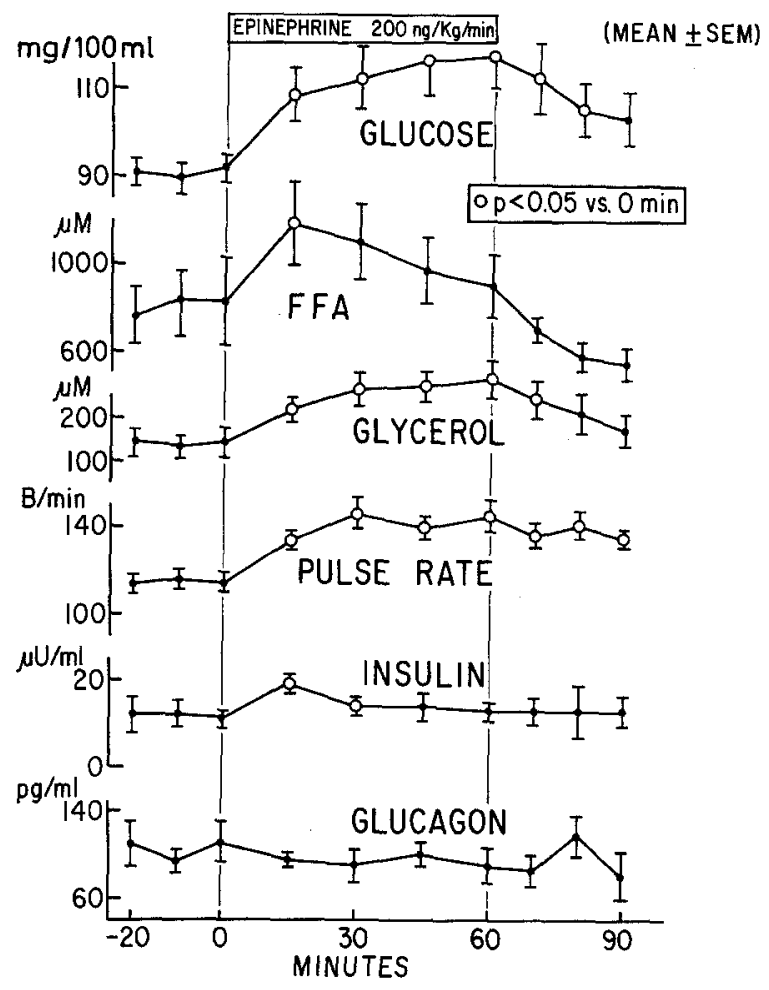

Fig. 2. The effect of epinephrine on heart rate and the plasma concentrations of glucose, FFA, glycerol, insulin and glucagon. Epinephrine was infused for one hour at a rate of $200 \mu \mathrm{g} / \mathrm{kg} / \mathrm{min}$ into 5 dogs. Mean \pm SEM are given. Statistically significant differences $(p<0.05)$ are indicated by open circles. Paired t-tests were used 


\section{Discussion}

The purported relationship between glucagon and lipolysis has been derived from two types of experiments: (a) the findings that pharmacological amounts of glucagon are lipolytic, as mentioned in the introduction, and (b) the fact that glucagon secretion decreased in experiments in which plasma levels of FFA were elevated $[20,10,17,6]$. The latter problem is discussed elsewhere [13].

Only a few investigators have tested the effects of glucagon by using it in physiological amounts. To delineate the role of a hormone in physiological and pathophysiological circumstances, only this approach can give a meaningful answer. It is, in addition, necessary to measure the hormone levels achieved by such infusions. The present experiments show that, in dogs, elevations of plasma glucagon in the physiologic range do not alter circulating FFA and glycerol levels. The fact that systemic insulin levels did not change minimized the possibility that augmented insulin concentrations could have counteracted a possible lipolytic effect of glucagon, as described by Liljenquist et al. [15]. An antilipolytic effect of the insulin present at baseline, however, cannot be excluded. Epinephrine administered in the same experimental conditions caused a significant increase in the levels of FFA and of glycerol. If plasma concentrations of FFA or of glycerol accurately reflect adipose tissue lipolysis [1] these results suggest that elevations of plasma glucagon in the physiologic or pathophysiologic range are not associated with increased adipose tissue lipolysis.

The present results also confirm those obtained by Cherrington et al. [3], who were unable to elevate FFA concentrations in pancreatectomized dogs by an infusion of increasing amounts of glucagon in the presence of a constant insulin infusion. Similarly, glucagon failed to elevate plasma FFA in humans in the studies of Schade et al. [19]. Our results are, however, in contradiction to those obtained by Lefèbvre et al. (14; see introduction). This difference is possibly due to the fact that Lefebvre infused glucagon into the portal rather than the systemic circulation. It might be, therefore, that elevated portal glucagon levels promote lipolysis from hepatic triglycerides or alter the uptake and/or metabolism of FFA in the liver. As reported recently by Gerich et al. [7] an infusion of physiologic amounts of glucagon in humans had lipolytic activity when infused together with somatostatin. This effect probably reflects the isolated effect of glucagon when other antilipolytic agents, among them insulin, are completely suppressed by the infusion of somatostatin. It appears therefore that glucagon can express its lipolytic effect on adipose tissue only when it is given either in pharmacologic amounts or when most antilipolytic agents, such as insulin, are excluded.

The effects of epinephrine as described here, are not new $[4,1]$. In conjunction with the results obtained with glucagon, however, they stress the primacy of the sympathetic nervous system in promoting lipolysis in situations of energy need.

Acknowledgements. We wish to thank Dr. John J. Hiebert, and Mr. Norman Sixt for their valuable help in the preparation of the animals, and Mmes. Velta Ramolins, Adacie Allen, Dzidra Rumba, Patricia Hatch and Anna Karass for their excellent technical assistance in the performance of these studies.

\section{References}

1. Björntorp, P., Schersten, T.: Effect of $\beta$-hydroxybutyrate on lipid mobilization. Amer. J. Physiol. 212, 683-687 (1967)

2. Cahill, G. F., Jr., Herrera, M. G., Morgan, A.P., Soeldner, J.S., Steinke, J., Levy, P.L., Reichard, G. A., Jr., Kipnis, D. M.: Hormone-fuel interrelationship during fasting. J. clin. Invest. 45, 1751-1969 (1966)

3. Cherrington, A., Vranić, M., Fono, P., Kovačević, N.: Effect of glucagon on glucose turnover and plasma free fatty acids in depancreatized dogs maintained on matched insulin infusions. Can. J. Physiol. 50, 946-954 (1972)

4. Dole, V.P.: A relation between non-esterified fatty acids in plasma and the metabolism of glucose. J. clin. Invest. 35, 150-154 (1956)

5. Gerich, J., Karam, J., Forsham, P.: Stimulation of glucagon secretion by epinephrine in man. J. clin. Endocr. 37, 479-481 (1973)

6. Gerich, J.E., Langlois, M., Schneider, V., Karam, J.H., Noac$\mathrm{co}, \mathrm{C}$. : Effects of alterations of plasma free fatty acid levels on pancreatic glucagon secretion in man. J. clin. Invest. $\mathbf{5 3}$ 1284-1289 (1974)

7. Gerich, J.E., Lorenzi, M., Bier, D. M., Tsalikian, E., Schneider, V., Karam, J.H., Forsham, P.H.: Effect of physiologic levels of glucagon and growth hormone on human carbohydrate and lipid metabolism - studies involving administration of exogenous hormone during suppression of endogenous hormone secretion with somatostatin. J. clin. Invest. 57, 875-884 (1976)

8. Hagen, J.H.: Effect of glucagon on the metabolism of adipose tissue. J. biol. Chem. 236, 1023-1027 (1961)

9. Hoffman, W.S.: A rapid photoelectric method for the determination of glucose in blood and urine. J. biol. Chem. 120, 51-55 (1937)

10. Madison, L.L., Seyffert, W.A., Unger, R.H., Barker, B.: Effect of plasma free fatty acids on plasma glucagon and serum insulin concentrations. Metabolism 17, 301-304 (1968)

11. Muller, W.A., Faloona, G.R., Unger, R.H.: Hyperglucagonemia in diabetic ketoacidosis. Its prevalence and significance. Amer. J. Med. 54, 52-57 (1973)

12. Muller, W.A., Aoki, T.T., Cahill, G.F., Jr.: Effect of alanine and glycine on glucagon secretion in postabsorptive and fasting man. J. clin. Endocr. 40, 418-425 (1975)

13. Muller, W.A., Aoki, T. T., Flatt, J.P., Blackburn, G.L., Egdahl, R.H., Cahill, G.F., Jr.: Effect of $\beta$-hydroxybutyrate, glycerol and free fatty acid infusions on glucagon and epinephrine secretion in dogs during acute hypoglycemia. Metabolism 25, 1077-1086 (1976) 
14. Lefèbvre, P.: The physiologic effect of glucagon on fat metabolism. Diabetologia 2, 130-132 (1966)

15. Liljenquist, J.E., Bomboy, J.D., Lewis, S.B., Sinclair-Smith, B., Felts, P.W., Lacy, W.W., Crofford, O.B., Liddle, G.W.: Effects of glucagon on lipolysis and ketogenesis in normal and diabetic man. J. clin. Invest. 53, 190-197 (1974)

16. Lindsey, C. A., Faloona, G. R., Unger, R. H.: Plasma glucagon in nonketotic hyperosmolar coma. J. Amer. med. Ass. 229, 1771-1773 (1974)

17. Luyckx, A.S., Lefèbvre, P.J.: Arguments for a regulation of pancreatic glucagon secretion by circulating plasma free fatty acids. Proc. Soc. exp. Biol. (N. Y.) 133, 524-528 (1970)

18. Robertson, R.P., Porte, D., Jr.: Adrenergic modulation of basal insulin secretion in man. Diabetes 22, 1-8 (1973)

19. Schade, D.S., Eaton, R.P.: Glucagon regulation of plasma ketone body concentration in human diabetes. J. clin. Invest. 56, 1340-1344 (1975)

20. Seyffert, W.A., Madison, L. L.: Physiologic effects of metabolic fuels on carbohydrate metabolism. I. Acute effect of elevation of plasma free fatty acids on hepatic glucose output, peripheral glucose utilisation, serum insulin and plasma glucagon levels. Diabetes 16, 765-776 (1967)

21. Sherwin, R.S., Fisher, M., Hendler, R., Felig, P.: Glucagon and glucose regulation in normal, obese and diabetic subjects. New Engl. J. Med. 294, 455-460 (1976)

22. Soeldner, J.S., Slone, D.: Critical variables in the radioimmunoassay of serum insulin using the double antibody technique. Diabetes 14, 771-779 (1965)

23. Trout, D.L., Estes, E.H., Jr., Friedberg, S. J.: Titration of free fatty acids of plasma; a study of current methods and a new modification. J. Lipid Res. 1., 199-202 (1960)

24. Unger, R.H., Aguilar-Parada, E., Muller, W.A., Eisentraut, A. M.: Studies of pancreatic alpha-cell function in normal and diabetic subjects. J. clin. Invest. 49, 837-848 (1970)

25. Unger, R.H., Orci, L.: The essential role of glucagon in the pathogenesis of diabetes mellitus. Lancet 1975 I, 14-16

Received: July 5, 1976, and in revised form: October 22, 1976

Dr. W. A. Muller

Institut de Biochimie Clinique

University of Geneva

Sentier de la Roseraie

CH-1211 Geneva 4

Switzerland 